\title{
3.3 Застосування задачі багаторукого бандита для максимізації пропускної здатності мережі
}

Задача про Багаторукого бандита (ББ) - одна 3 головних задач в теорії прийняття рішень та навчання 3 підкріпленням, мета якої оптимальне розподілення ресурсів в умовах невизначеності [202, 204, 205].

Навчання з підкріпленням - розділ у машинному навчанні, дає можливість агенту вчитися в інтерактивному середовищі методом. Агент отримує винагороду або покарання на кожну дію, таким чином формується досвід.

Як і у навчанні зі вчителем, так і навчання з підкріпленням використовують залежність між входом і виходом, але на відмінунавчанні зі вчителем, де зворотний зв'язок, що надається агенту, $є$ правильним набором дій для виконання завдання, навчання 3 підкріплення використовує нагороди та покарання як сигнали для позитивної та негативної поведінки [203].

У порівнянні 3 навчанням без вчителя, навчання 3 підкріпленням відрізняється з точки зору цілей. Хоча метою некерованого навчання $є$ пошук подібності та відмінності між точками даних, у процесі навчання з підкріплення мета полягає у пошуку відповідної моделі дій, яка б максимізувала загальну сукупну винагороду агента. На рис. 1 представлена основна ідея та елементи, що беруть участь моделі навчання з підкріпленням.

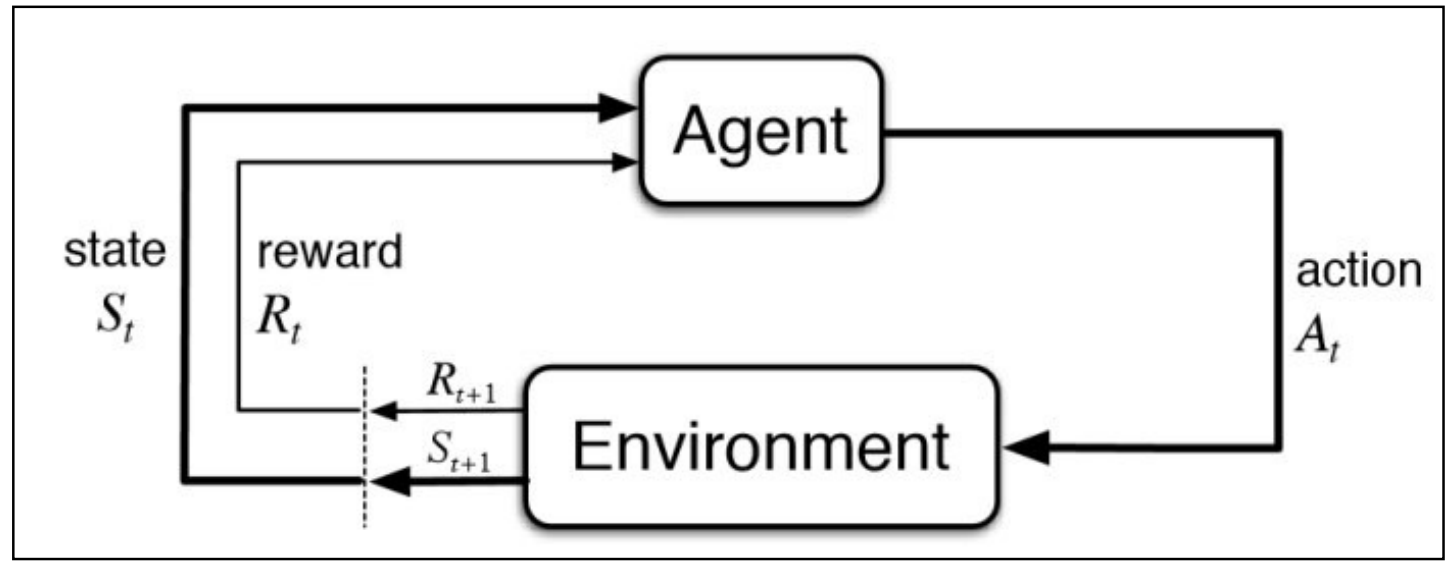

Рис.1. Модель навчання з підкріпленням.

Задачу ББ Бернуллі можна описати як кортеж значень $\langle A, R\rangle$, де $€ K$ автоматів 3 вірогідністю винагороди $P_{K}=\left\{p_{1}, p_{2}, \ldots, p_{K}\right\}$. На кожному кроці $t$ 
виконуємо дію $a$ - тягнемо за важіль автомата - та отримуємо винагороду $r$. $A$ - це множина дій, що відображує взаємодію з автоматом $K_{i}$. Значення дії $a$ - це очікувана винагорода, $Q(a)=E[a]=p$. Якщо дія $a_{t}$ на кроці $t_{i}-$ автомата, тоді $Q\left(a_{t}\right)=p_{i} \cdot R$ - це функція винагород. У випадку ББ, ми отримуємо винагороду $r$ в стохастичній формі. На кожному кроці $r_{t}=R\left(a_{t}\right)$ поверне винагороду в розмірі 1 з вірогідністю $Q\left(a_{t}\right)$ або 0 [202].

Дана модель є спрощеною версією ланцюга Маркова, так як відсутній стан $S$. Мета - максимізувати накопичувальну винагороду $\sum_{t=1}^{T} r_{t}$. Якщо відома оптимальна дія з найкращою винагородою, тоді мета мінімізувати потенційні втрати через вибір неоптимальної дії.

Оптимальна вірогідність винагороди $p^{*}$ оптимальної дії $a^{*}$ : $p^{*}=Q\left(a^{*}\right)=Q(a)=p_{i}$. Функція втрат - це загальні втрати від вибору неоптимальних дій $а$ на кроках $T: L_{T}=E\left[\sum_{t=1}^{T}\left(p^{*}-Q\left(a_{t}\right)\right][205]\right.$.

Дилема «Досліджуй та використовуй» одна з основних проблем навчання в підкріпленням. Агенти-алгоритми хочуть застерегти себе від можливих втрат, експериментуючи 3 субоптимальними варіантами, щоб з'ясувати їх рентабельність. Якщо їх рентабельність виявиться високою дані варіанти можна використовувати частіше. Друга перевага від досліджень варіантів - це оцінка невизначеності.

$\varepsilon$ - жадібний алгоритм обирає найкращу дію більшість часу, але час від часу проводить випадкові дослідження. Значення дії оцінюється враховуючи попередній досвід шляхом усередненням винагороди, що пов'язана 3 ціллю дії $a$, яку спостерігали до поточного кроку $t: \hat{Q}_{t}(a)=\frac{1}{N_{t}(a)} \sum_{j=1}^{t} r_{j}\left[a_{j}=a\right]$, де 1 - це бінарний індикатор функції та $N_{t}(a)$ - кількість обраних дій $N_{t}(a)=\sum_{j=1}^{t} 1\left[a_{j}=a\right]$ [203]. 
Згідно даного алгоритму, з невеликою вірогідністю $\varepsilon$, дія $a$ обирається випадково. Але в більшості випадків, тобто 3 вірогідністю $1-\varepsilon$, обирається найкраща дія, яка була обрахована до кроку $t: a_{t}^{*}=\arg \arg Q_{t}(a)$.

Щоб уникнути неефективного навчання, один підхід полягає у зменшенні параметра $\varepsilon$ в часі, а інший - дослідження варіантів з високою невизначеністю i, отже, надання переваги діям, для яких ми ще не маємо оцінки. Або іншими словами, слід надати перевагу дослідженню дій із сильним потенціалом, щоб отримати оптимальне значення [205].

Алгоритм UCB вимірює цей потенціал верхньою межею значення винагороди $U_{t}(a)$, так що справжнє значення буде нижче за межу $Q(a) \leq Q_{t}(a)+U_{t}(a)$ з високою вірогідністю. Верхня межа $U_{t}(a)-$ це функція від $N_{t}(a)$. Найбільша кількість спроб $N_{t}(a)$ повинна давати найменшу межу $U_{t}(a)$.

В сімействах алгоритмів UCB ми завжди слід обирати більш жадібну дію, щоб максимізувати верхню межу довіри: $a_{t}^{U C B}=\arg \max _{a \in A} Q_{t}(a)+U_{t}(a)$ [204].

Тепер постає питання - як досягти верхню межу довіри. Існує декілька способів. Верхня межа обраховується за наступною формулою: $U_{t}(a)=\sqrt{\frac{2 \log t}{N_{t}(a)}} \cdot \mathrm{A}$ винагорода обраховується за наступною формулою: $a_{t}^{U C B}=\arg \max _{a \in A} Q_{t}(a)+\sqrt{\frac{2 \log t}{N_{t}(a)}}$ [202].

Виконаємо сем плювання Томпсона, де на кожному кроці $t$, обирається дія a відповідно 3 вірогідністю того, що вона $\epsilon$ оптимальною: $p\left(h_{t}\right)=P\left[h_{t}\right]=E_{R \mid h_{t}}[1(a=\arg \arg Q(a))]$, де $p\left(h_{t}\right)-$ це вірогідність вибрати дію $a$ в даній історії $h_{t}[202]$.

Для ББ логічно припустити, що $Q(a)$ відповідає Бета-розподілу, так як $Q(a)$ - це вірогідність успіху $p$ в розподілі Бернуллі (Бета-розподіл та розподіл Бернуллі $є$ апріорно зв’язані). Значення Бета $(\alpha, \beta)$ лежить в інтервалі [201, 202]. $\alpha$ та $\beta$ відповідають підрахункам успіхів та невдач отримати винагороду. 
Спочатку ініціалізуються Бета параметри $\alpha$ та $\beta$, що базуються на деяких попередніх знаннях чи тверджень про дію. До прикладу: $\alpha=1$ та $\beta=1$, очікувана вірогідність винагороди 50\%, але впевненості в цьому немає. $\alpha=1000$ та $\beta=900$ : ми впевнені, що вірогідність винагороди 10\% [204].

На кожному кроці $t$ обирається очікувана винагорода $Q(a), 3$ попереднього розподілу Бета $\left(\alpha_{i}, \beta_{i}\right)$ для кожної дії. Краща дія обирається серед варіантів $a_{t}^{T S}=\arg \arg Q(a)$. Після того справжня винагорода буде знайдена, можна оновити Бета-розподіл: $\alpha_{i} \leftarrow \alpha_{i}+r_{t} 1\left[a_{t}{ }^{T S}=a_{i}\right] \quad \beta_{i} \leftarrow \beta_{i}+(1-r) 1\left[a_{t}^{T S}=a_{i}\right]$ [203].

Семплювання Томпсона використовує ідею зіставлення вірогідностей (probability matching). Так як винагорода $Q$ оцінюється 3 апостеріорних розподілів, кожна з вірогідностей рівнозначна вірогідності того, що відповідна дія є оптимальною.

Сформуємо реальну бізнес-задачу: нехай рекламна кампанія розміщує на веб-сторінці 10 різноманітних РБ, що орієнтовані на певну групу користувачів. Зібрані дані, що відображають 10 РБ по стовпцях та 10000 відвідувань вебсторінки користувачами і їх кліки на банери. 1 - якщо на РБ клікнули, та 0 - в іншому випадку. На рис. 2 наведено приклад з початкового набору даних [205].

\begin{tabular}{rrrrrrrrrrr} 
& Ad 1 & $\operatorname{Ad} 2$ & $\operatorname{Ad} 3$ & $\operatorname{Ad} 4$ & $\operatorname{Ad} 5$ & $\operatorname{Ad} 6$ & $\operatorname{Ad} 7$ & $\operatorname{Ad} 8$ & $\operatorname{Ad} 9$ & $\operatorname{Ad} 10$ \\
\hline 0 & 1 & 0 & 0 & 0 & 1 & 0 & 0 & 0 & 1 & 0 \\
1 & 0 & 0 & 0 & 0 & 0 & 0 & 0 & 0 & 1 & 0 \\
2 & 0 & 0 & 0 & 0 & 0 & 0 & 0 & 0 & 0 & 0 \\
3 & 0 & 1 & 0 & 0 & 0 & 0 & 0 & 1 & 0 & 0 \\
4 & 0 & 0 & 0 & 0 & 0 & 0 & 0 & 0 & 0 & 0 \\
5 & 1 & 1 & 0 & 0 & 0 & 0 & 0 & 0 & 0 & 0 \\
6 & 0 & 0 & 0 & 1 & 0 & 0 & 0 & 0 & 0 & 0 \\
7 & 1 & 1 & 0 & 0 & 1 & 0 & 0 & 0 & 0 & 0 \\
8 & 0 & 0 & 0 & 0 & 0 & 0 & 0 & 0 & 0 & 0 \\
9 & 0 & 0 & 1 & 0 & 0 & 0 & 0 & 0 & 0 & 0
\end{tabular}

Рис. 2. Перші 10 рядків зібраних даних.

Дізнаємось, рейтинг кліків кожного РБ. Для цього скористаємося наступною формулою: $C T R=\frac{\text { кількістькліків }}{\text { кількістьпоказів }} * 100 \%$.

На рис. 3 зображені обрахунки РК. Також можна зробити висновок, що РБ під номером 5 - найпопулярніший варіант. 


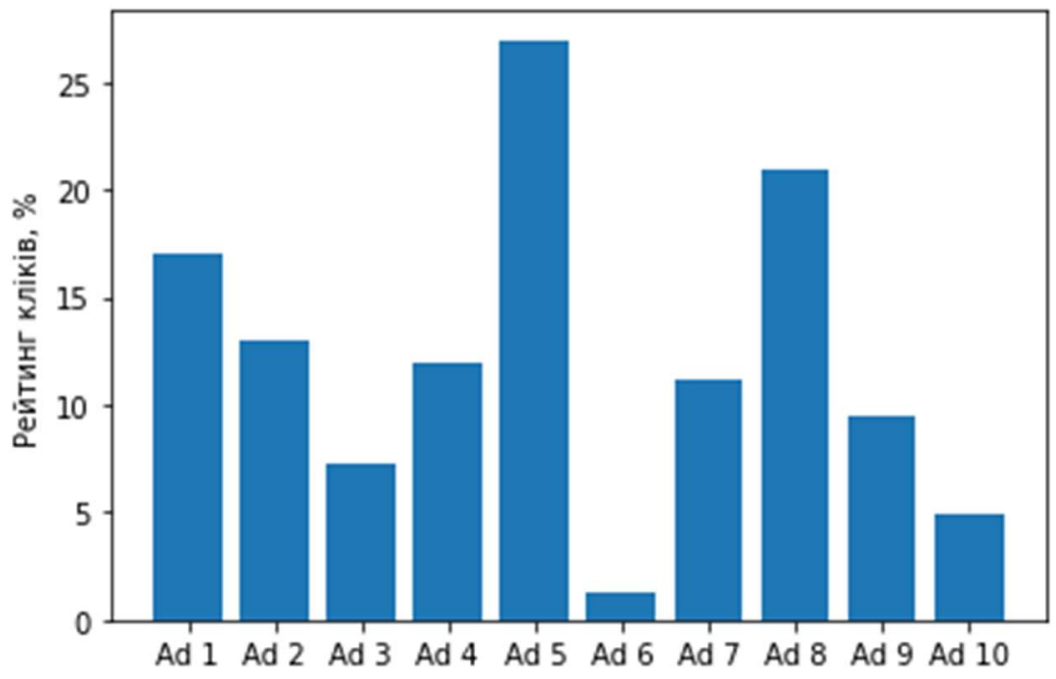

Рис. 3. Рейтинг кліків рекламних банерів

Структурно програма складається 35 класів:

Клас МАВ - уособлює собою ББ. Основне завдання класу - обрахунок реальної вірогідності отримати винагороду та сам механізм генерування винагороди.

Клас Environment() - уособлює собою середовище, в якому діє ББ. Приймає об'єкт класу МАВ(). Основне завдання класу - запуск стратегії на $t$ кроків, оновлення втрат на кожному кроці $t$.

Класи EpsilonGreedy(Environment), ThompsonSampling(Environment), UCB1(Environment) - уособлює стратегії ББ. Основне завдання класів обрахунок очікуваної винагороди та вибору дії, що $є$ найоптимальнішою на кожному кроці $t$. Саме механізм вибору дії різний в кожній стратегії. Нижче подано реалізацію найоптимальнішої дії $a$ на кожному кроці $t$.

Алгоритм для EpsilonGreedy(Environment)

Ініціалізується вектор очікуваної вірогідності отримати винагородур.

Для кожного крокуагента:

1. Генерується випадкове значенняг від 0 до 1

2. Якщо $r$ менше від $\varepsilon$, тообирається випадковий банер.

Якщогбільше за $\varepsilon$, то обирається банер 3 найбільшою вірогідністю отримати винагородуз вектора $p$.

3. Агент отримує винагороду або штраф за обраний банер. 
4. Оновлююється вектор $p$.

Алгоритм для ThompsonSampling(Environment)

Ініціалізуються вектори для кожного банера бути обраним/необраним.

Для кожного кроку агента:

1.Генерується вектор с за Бета-розподілом з відповідними значеннями $\alpha$ та $\beta$ з векторів $a$ та $b$ відповідно.

2. Обирається найбільше значення у векторі $c$. Індекс обраного значення відповідає номеру банера.

3. Агент отримує винагороду або штраф за обраний банер.

4. Якщо отримано винагороду то оновлюється вектор $a$, якщо - ні вектор $b$.

Алгоритм для UCB1(Environment).

Ініціалізується вектор очікуваної вірогідності отримати винагородур та крок $t=0$.

Для кожного крокуагента:

1. Обирається банер як максимальне значення 3 суми наявних вірогідностей та верхної межі.

2. Агент отримує винагороду або штраф за обраний банер.

3. Оновлюється вектор $b$.

Один 3 методів ефективності алгоритмів є концепція втрат (regret). Це різниця між очікуваними та реальними даними. Втрати алгоритму щодо своєї дії повинні бути якомога нижчою. Нижче, на рис. 4, подані кумулятивні витрати на кожному кроці $t$. Аналізуючи графік нижче, можна прийти до висновку, що найменші втрати у СТ. 


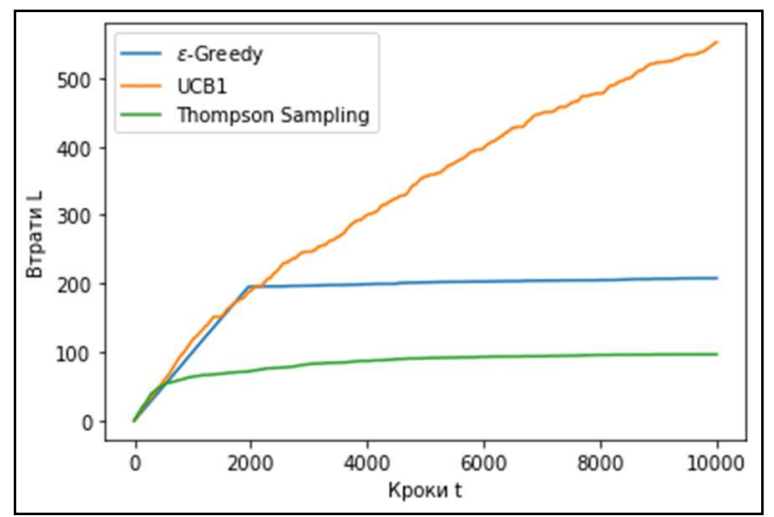

Рис. 4. Кумулятивні витрати.

На рис. 5 зображено графік реальний та обрахованих вірогідностей для кожного банеру відповідно до алгоритму.

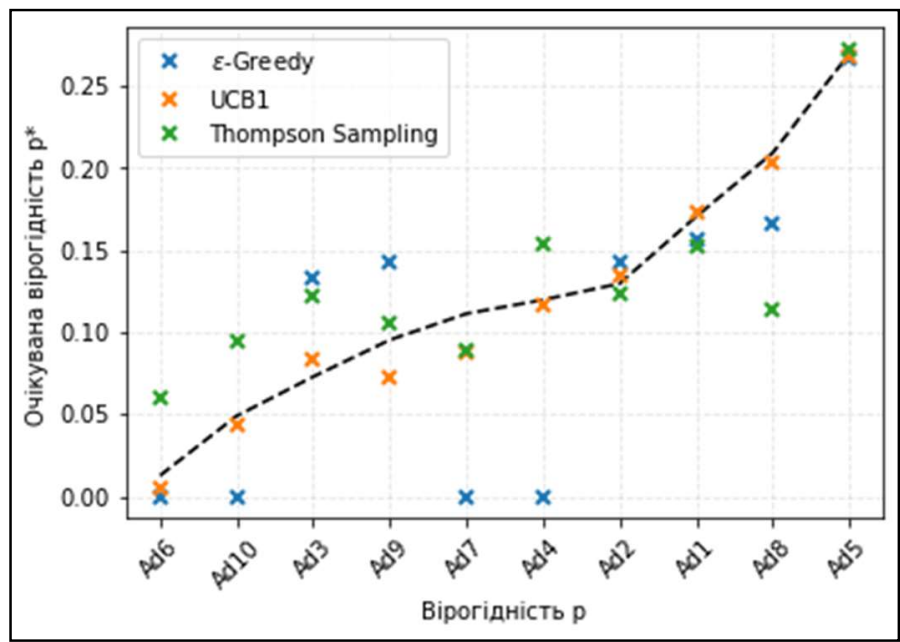

Рис. 5. Графік реальної та очікуваної вірогідності за результатами експеримента.

На рис. 6 показано як часто даний банер було обрано як оптимальний. Усі алгоритми обранли дійсно найпопулярніший банер, але UCB1 частіше робив дослідження.

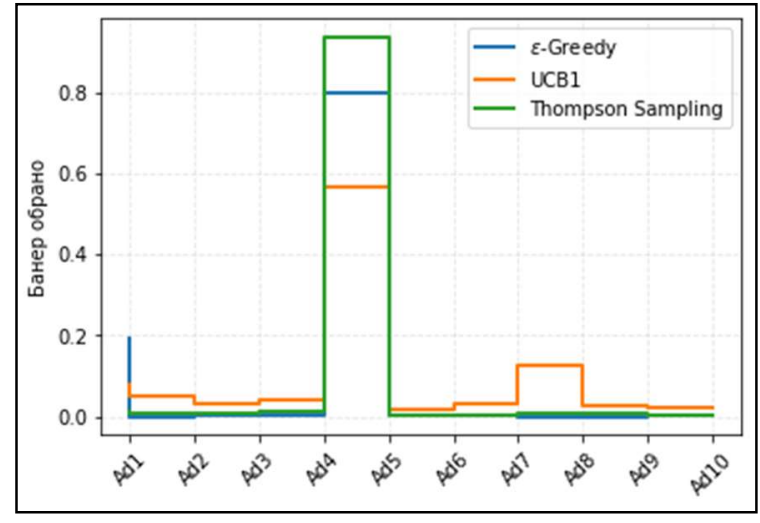

Рис. 6. Оптимальний банер 
За результатами роботи можна побачити, алгоритми ББ завжди забезпечують оптимальний варіант. Конкретний вибір алгоритму залежить від того, чи бажає користувач визначити пріоритетний автомат (в даному випадку рекламний банер) чи динамічний аналіз, а також передбачуваний розмір та тривалості експерименту.

$\varepsilon$ - жадібний та UCB1 алгоритми змогли у кінцевому випадку знайти оптимальний банер, не жертвуючи дослідженням усіх варіантів та виявляти статистичні відмінності між ними, тоді як СТ оптимізований для максимізації довгострокового результату. Але хоча $\varepsilon$ - жадібний алгоритм і досліджував середовище, коли $\varepsilon$ встановлено занадто низьким, $\varepsilon$-жадібний алгоритм може в найкращому випадку захопити найбільше значення, але поведінка алгоритму також стає досить нестабільною. Тому, підсумовуючи, UCB-1 - це правильний вибір алгоритму ББ для динамічних, а СТ - для статичних даних в інформаційній мережі. 